\title{
Application of 17-7 Precipitation-hardenable Stainless Steel in Dentistry
}

\author{
R. G. CRAIG, H. J. SLESNICK, * and F. A. PEYTON \\ University of Michigan School of Dentistry, Ann Arbor, Michigan
}

Several alloys described as stainless steel which resist tarnish and corrosion in the mouth are being used for a variety of dental appliances and instruments. Probably the greatest application of stainless steel is for orthodontic arch wires and bands, while a more limited use is for temporary space maintainers and crown forms. Root-canal files and reamers designed for endodontic operations also are being fabricated from stainless steel. For each of these applications there are advantages to having an alloy which will respond to hardening heat treatments.

Stainless steels generally can be classed as ferritic, martensitic, or austenitic. Although the properties and physical metallurgy of these stainless steeis is quite well known, the use of precipitation-hardenable stainless steels has developed since 1946.1, 2 Since this time, austenitic, martensitic, and semiaustenitic stainless steels have been developed which are subject to precipitation hardening. Of these three types of precipitationhardenable stainless steels the semiaustenitic type is capable of producing the higheststrength materials.

The treatment of the semiaustenitic stainless steel consists of three separate parts: $:^{3-5}$ (1) a solution treatment at $1,950^{\circ} \mathrm{F}$., (2) transformation of the austenite to martensite, and (3) the precipitation of hardening phases within the martensite. The initial solution treatment results in the solution of

This study was supported in part by USPHS Research Grant DE-01 234 from the National Institute of Dental Research, $\mathrm{Na}$ tional Institutes of Health, Bethesda, Md.

A portion of this paper was taken from a thesis submitted to the Horace H. Rackham School of Graduate Studies as partial fulfilment of the requirements for the degree of Masters of Science (Orthodontics).

Presented in part at the 41st Annual Meeting of the International Association for Dental Research, March 23, 1963, Pittsburgh, Pennsylvania.

Received for publication July 21, 1964.

* Present address, West Valley Professional Center, 5150 Graves Avenue, San Jose, Calif. carbon and the precipitation-hardening elements, and the matrix is austenite containing 5-20 per cent $\delta$-ferrite. The transformation of the austenite to martensite may be accomplished by a thermal treatment of 90 minutes at $1,400^{\circ} \mathrm{F}$. followed by cooling to $60^{\circ} \mathrm{F}$. within 60 minutes or 10 minutes at $1,750^{\circ} \mathrm{F}$., cooled in air to room temperature and then refrigerated at $-100^{\circ} \mathrm{F}$. for 8 hours. The transformation of austenite to martensite also may be carried out by a mechanical treatment where the solutiontreated steel is cold-worked 60 per cent. Any of these thermal or mechanical treatments which result in the transformation of austenite to martensite cause a hardening of the steel. A further hardening results when coherent precipitates form within the martensitic matrix when the steel is aged at temperatures of 900 to $1,050^{\circ} \mathrm{F}$. for a period of 60-90 minutes, the temperature and time depending on the extent of strained lattice present. X-ray analysis has shown that the presence of a compound exists which is thought to be an aluminum and nickel compound.

The semiaustenitic precipitation-hardenable stainless steel offers the advantages of being highly ductile after the solution treatment and can be formed readily in this condition. The material can be hardened by the transformation of austenite to martensite with high strength and low elongation but it will still withstand moderate forming operations. Further increases in strength and decreases in elongation result from the controlled precipitation of a metallic compound after forming operations are completed.

The purpose of this study was to investigate the possibility of using the semiaustenitic precipitation-hardenable stainless steels as orthodontic arch wires and to compare these materials with the $18-8$ austenitic 
TABLE 1

Tensile Properties of 17-7 PH Stalniess Steel

\begin{tabular}{|c|c|c|c|c|c|c|}
\hline \multirow{2}{*}{ CONDITION } & \multicolumn{2}{|c|}{$\begin{array}{c}\text { YIELd Strength } \\
(0.1 \text { Per Cent OffSet })\end{array}$} & \multicolumn{2}{|c|}{ Tensile Strength } & \multicolumn{2}{|c|}{ Elastic Modulus } \\
\hline & $\operatorname{Psi} \times 10^{5}$ & S.D. & Psi $\times 10^{5}$ & S.D. & Psi $\times 10^{6}$ & S.D. \\
\hline Condition "C" ". & 2.53 & 0.14 & 3.02 & 0.29 & 29.5 & 0.7 \\
\hline 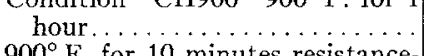 & 3.15 & .11 & 3.55 & .08 & 30.4 & 0.5 \\
\hline $\begin{array}{l}900^{\circ} \mathrm{F} \text {. for } 10 \text { minutes resistance- } \\
\text { heating }\end{array}$ & 2.72 & .12 & 3.42 & .06 & 30.7 & 0.9 \\
\hline $\begin{array}{l}\text { Prestressed } 900^{\circ} \mathrm{F} \text {. for } 10 \text { minutes } \\
\text { resistance-heating. }\end{array}$ & 2.77 & 0.18 & 3.49 & 0.05 & 30.3 & 2.0 \\
\hline
\end{tabular}

stainless steels and the cobalt-chromiumnickel* wires used in orthodontics.

\section{Materials and Methods}

The semiaustenitic stainless steel selected for this investigation was $17-7 \mathrm{PH} \dagger$ which has the following composition: $16.00-18.00$ per cent $\mathrm{Cr} ; 6.50-7.75$ per cent $\mathrm{Ni} ; 0.09$ per cent max. $\mathrm{C} ; 0.75-1.50$ per cent $\mathrm{Al} ; 1$ per cent $\max . \mathrm{Mn} ; 0.04$ per cent $\max . \mathrm{P}$; 0.04 per cent max. S; 1 per cent max. $\mathrm{Si}$; and the balance $\mathrm{Fe}$. The stainless steel was obtained in the form of round wires 0.014 and 0.022 inches in diameter $\ddagger$ which had been cold-worked and therefore was in a strain. hardened martensitic form. The precipitation-hardening treatment consisted of heating at $900^{\circ} \mathrm{F}$. in a furnace for a period of 60 minutes or in a resistance heater $\$$ for shorter times of $10-15$ minutes.

Two 18-8 stainless steel $\|$ and four cobaltchromium-nickel wires which are used as orthodontic arch wires having diameters of 0.014 and 0.022 inches in diameter were used for purposes of comparison. The nominal composition of the 18-8 stainless steel is $17-$ 19 per cent $\mathrm{Cr} ; 8-10$ per cent $\mathrm{Ni} ; 0.08-0.2$ per cent $\mathrm{C} ; 2.0$ per cent max. Mn; while that of the cobalt-chrome-nickel alloy is 40 per cent $\mathrm{Co} ; 20$ per cent $\mathrm{Cr} ; 15$ per cent $\mathrm{Ni} ; 7$ per cent Mo; 2 per cent Mn; 0.15 per cent C; 0.04 per cent $\mathrm{Be}$; and the balance iron. The cobalt-chromium-nickel alloy was used in

\footnotetext{
* Elgiloy, Elgin National Watch Co., Elgin, Jll.

† Armco Steel Corp., Middletown, Ohio.

\# National-Standards Co., Niles, Mich

\$ The Warwec Co., Pittsburgh, $\mathrm{Pa}$.

I Rocky Mountain Metal Products Co, and Unitek, Denver, Colo.
}

four conditions which were classed as soft, ductile, semispring temper and spring temper.

The tensile properties of yield strength, tensile strength, and elastic modulus were determined on 2 -inch lengths of wires on a testing machine\# at a deformation rate of 0.02 inches/minute in conjunction with 1 inch snap-on type extensometer** at a magnification of the strain of 250 times. The tensile properties were calculated from the plot of the load versus the strain on the basis of the original diameter of wires. The yield strength at 0.1 per cent offset was calculated rather than the proportional limit, since it was a more reproducible value. In several instances the wires were prestressed at a value halfway between the yield strength and the ultimate strength for 10 minutes, after which the load was relieved and then the tensile properties were measured. The values reported represent average values of ten separate determinations on samples from different lengths of wire selected at random from the main source of material.

The qualities in bending were evaluated on a stiffness tester $t+$ which allowed the determination of the bending moment versus the angular deflection on a span of wire 1 inch in length. ${ }^{6}$ Again, the test samples were selected at random, and the curves shown represent averages of 3 individual determinations.

\footnotetext{
* Reihle 'Testing Machine, American Machines and Metals, nc., East Moline, Ill

** Baldwin B-3m differential transformer-type extensometer, Wiedemann Machine Co., King of Prussia, Pa.

†† Tinius Olsen 6-inch stiffness tester, Tenius Olsen Testing Machine Co., Philadelphia, $\mathrm{Pa}$.
} 
The resistance to breakage by cold bending was measured by a method reported by Craig and Peyton ${ }^{6}$ in the evaluation of rootcanal files and reamers. The method consists of bending the wire in alternating $90^{\circ}$ bends until the sample fractures. The data reported are averages of ten separate determinations on randomly selected wires of the various materials.

The microhardness of the wires was determined on specimens which were imbedded in a room-temperature curing plastic. The specimens were prepared by the use of a series of silicon carbide papers followed by polishing on a wheel using velvet and a metallographic polishing compound.* A Knoop indentert was used with a 500 -gm. load and a 15-second contact time to obtain the microhardness values. The values reported represent averages of ten separate readings taken on four individual samples of wire selected from different lengths of material.

\section{Results and Discussion}

The tensile properties of the $17-7 \mathrm{PH}$ wires of 0.022 -inch diameter are listed in Table 1. Condition "C" refers to the material which has been solution-treated and then transformed from austenite to martensite by cold-working, and condition " $\mathrm{CH}$ 900 " indicates that the material in condition "C" has been precipitation-hardened by aging in a furnace for 1 hour at $900^{\circ} \mathrm{F}$. followed by cooling in air. It should be pointed out that the 17-7 PH wire in condition "C" had high-strength qualities indicated by the yield strength of 253,000 psi and the tensile strength of 302,000 psi. Further increases in strength resulted from the aging treatment at $900^{\circ} \mathrm{F}$. are shown by the higher values of 315,000 and 355,000 psi for the yield streng th and tensile strength, respectively. Since 1 hour at $900^{\circ} \mathrm{F}$. is a long period of time for age-hardening, shorter times at $900^{\circ} \mathrm{F}$. in a resistance heater as well as a furnace were used, and the tensile properties were determined. The values for the tensile properties are reported in Table 1 for aging at $900^{\circ} \mathrm{F}$. of 10 minutes, and only a slight increase was observed in the yield strength and ultimate

\footnotetext{
* "C-RO," Metallographic Polishing Compound.

† Wilson Tukon Hardness Tester, American Chain and Cable Co., Inc., New York, N.Y.
}

strength. The difference between the two means of the yield strength and the two means of the ultimate strength are significant at the 99 per cent confidence level using the Student $t$-test. Higher temperatures than $900^{\circ} \mathrm{F}$. for short periods is of little assistance, since more rapid aging takes place but lower optimum properties are attained. Prestressing the wires above the yield strength did not alter the physical properties, and therefore normal-forming operations do not seem to affect the tensile properties of $17-7 \mathrm{PH}$. It should be mentioned that as the tensile properties increase during the precipitation hardening for 1 hour at $900^{\circ} \mathrm{F}$., the ductility decreases as shown by a decrease in the per cent elongation from 5 to 2 per cent. ${ }^{3}$ The elastic modulus, as seen in Table 1, remained unchanged during the precipitation-hardening procedures.

The tensile properties of the two 18-8 stainless steels and the cobalt-chromiumnickel alloy in four conditions of hardness are reported in Table 2, together with the previous values of 17-7 PH stainless steel in condition "C." The values for the elastic moduli are not included, since no significant variations from $27-30 \times 10^{-6}$ psi were observed. It can be seen that the yield strengths of the 18-8 stainless-steel wires, 0.022 inch in diameter, were significantly less than that of the 17-7 PH stainless steel in condition "C," although the tensile-strength values were approximately the same.

The cobalt-chromium-nickel alloy is brought to optimum properties by a combination of cold-working and heat treatment, the latter being carried out at temperatures of $600-1,000^{\circ} \mathrm{F}$. for periods of 3-5 hours. Annealing is not recommended, since it removes the stress induced by cold-work, and the maximum properties are not regained by further heat treatments. Since these work-hardening and heat-treatment procedures are not practical in dental operations, this material is supplied in four different conditions noted as soft, ductile, semispring temper, and spring temper. The yield strength and the ultimate tensile strength of the four conditions increased from 130,000 and 204,000 psi for the soft to 175,000 and 309,000 psi for the spring-temper condition, and therefore the tensile properties of the spring-temper alloy were comparable to those of the stainless steels, except that the 
TABLE 2

TENSILE Properties OF Wires

USED IN ORTHODONTICS

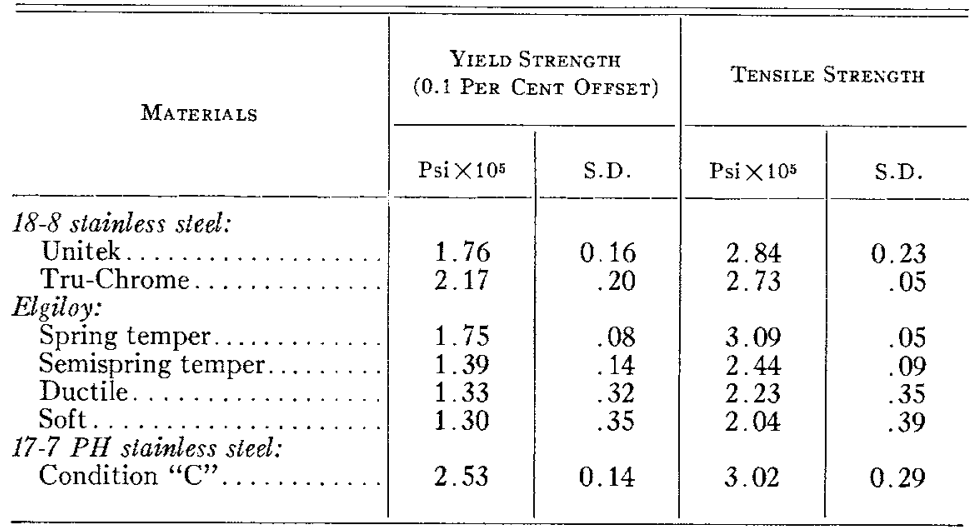

yield strength of the 17-7 PH stainless steel was higher.

The bending properties of 0.014 -inch diameter 17.7 PH stainless-steel wire are shown in graphic form in Figure 1, where the bending moment in inch pounds is plotted against the angular deflection in degrees over a span of 1 inch. For purposes of comparison, the bending moment-angular deflection curves are shown in Figures 2 and 3 for 0.014- and 0.022-inch diameter wires of 18-8 stainless steel and the cobalt-chromium-nickel alloy. As would be expected from the tensile properties of $17-7 \mathrm{PH}$ stainless steel in various conditions, the stiffness of the material did not change, but the bending moment required to produce a permanent bend in the wire increased with the precipitation-hardening treatment at $900^{\circ} \mathrm{F}$. Also, the precipitation-hardening treatment at the recommended time of 1 hour at $900^{\circ} \mathrm{F}$. produced a greater increase than the 15minute treatment in the resistance heater.

The permanent set after various angular deflections of 17-7 PH and 18-8 stainlesssteel wires is shown in Figure 4. For example, permanent set after 30 - and 60 -degree bends was 1 degree and 9 degrees for 17-7 PH stainless steel in condition " $\mathrm{C}$," while it was 0 degree and 3 degrees, respectively, after heat treatment to condition "CH900." Comparable values of 0 degree and 5 degrees were obtained on 18-8 stainless steel.

Care should be exercised to avoid over- heating the 17-7 $\mathrm{PH}$ wires, as indicated by the poor resistance to permanent bending for the wire heated to approximately $1,300^{\circ} \mathrm{F}$. for 15 minutes (see Fig. 1). This higher temperature has produced overaging, or reversion of the martensite to austenite, and thus the bending moment required to produce a permanent deflection was lowered drastically.

The bending moment-angular deflection curves of the cobalt-chromium-nickel alloy shown in Figures 2 and 3 are in the order of their ductility, with the spring-temper wire having the greatest resistance to permanent bending and the soft wire having the least resistance. The resistance of the 18-8 and 17-7 PH stainless steel in condition " $\mathrm{C}$ " to permanent bending was greater than any of the four conditions of the cobalt-chromiumnickel alloy. It should be pointed out that the resistance to bending of the $17-7 \mathrm{PH}$ stainless steel in condition "CH900" would be higher than that of the 18-8 stainless steel or the 17-7 PH stainless steel in condition "C."

The Knoop-hardness values for the various wires are listed in Table 3 . The trend in hardness values is in the same order as the tensile properties reported in Tables 1 and 2 . The hardness measurement, therefore, is a good general indication of the strength qualities and has special application in the evaluation of changes in localized areas of wires as a result of soldering, spot-welding, or rupture. $^{7}$ 


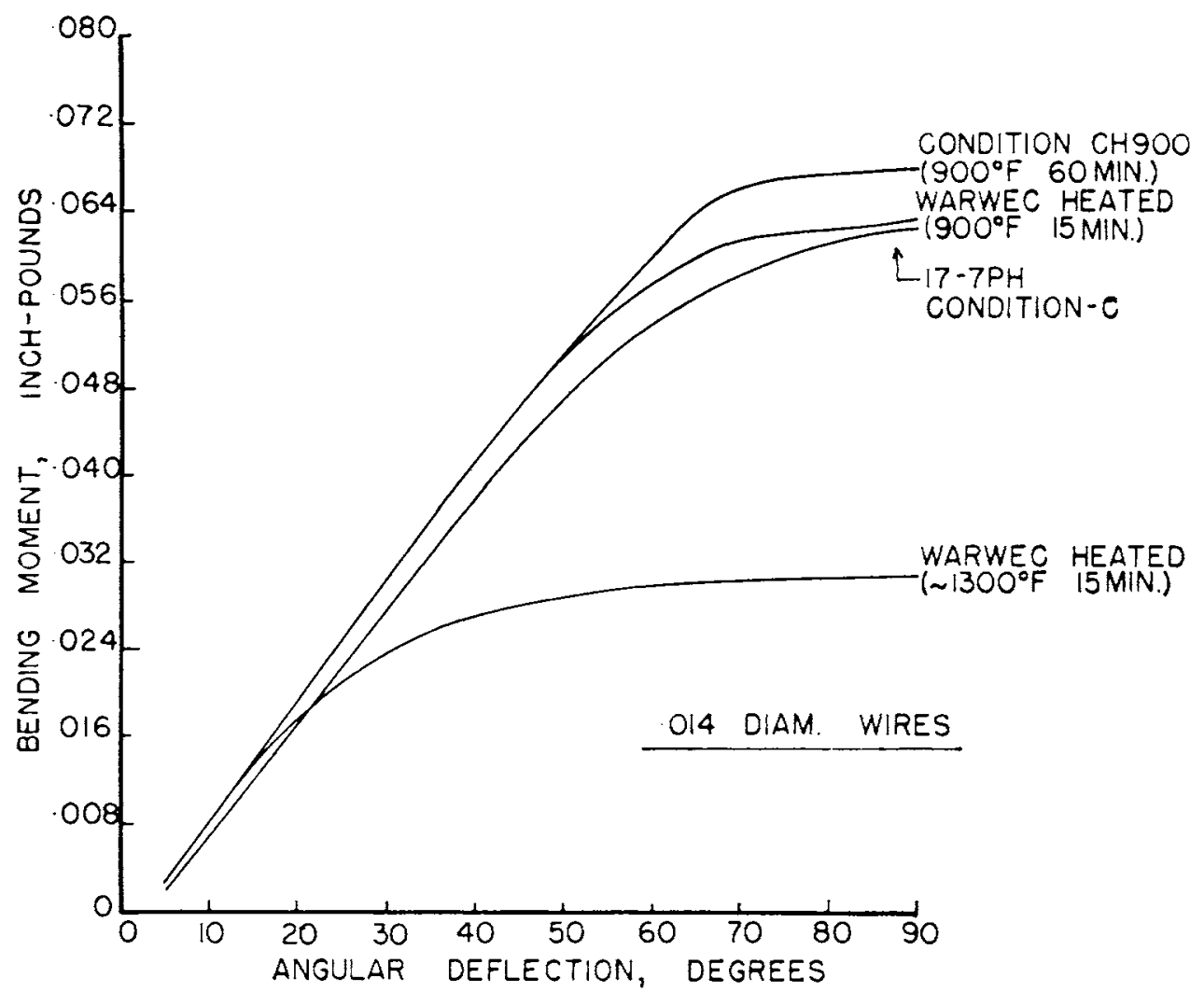

FIG. 1.-Bending moment-angular deflection curves for 17-7 $\mathrm{PH}$ stainless-steel wires after various hardening treatments.

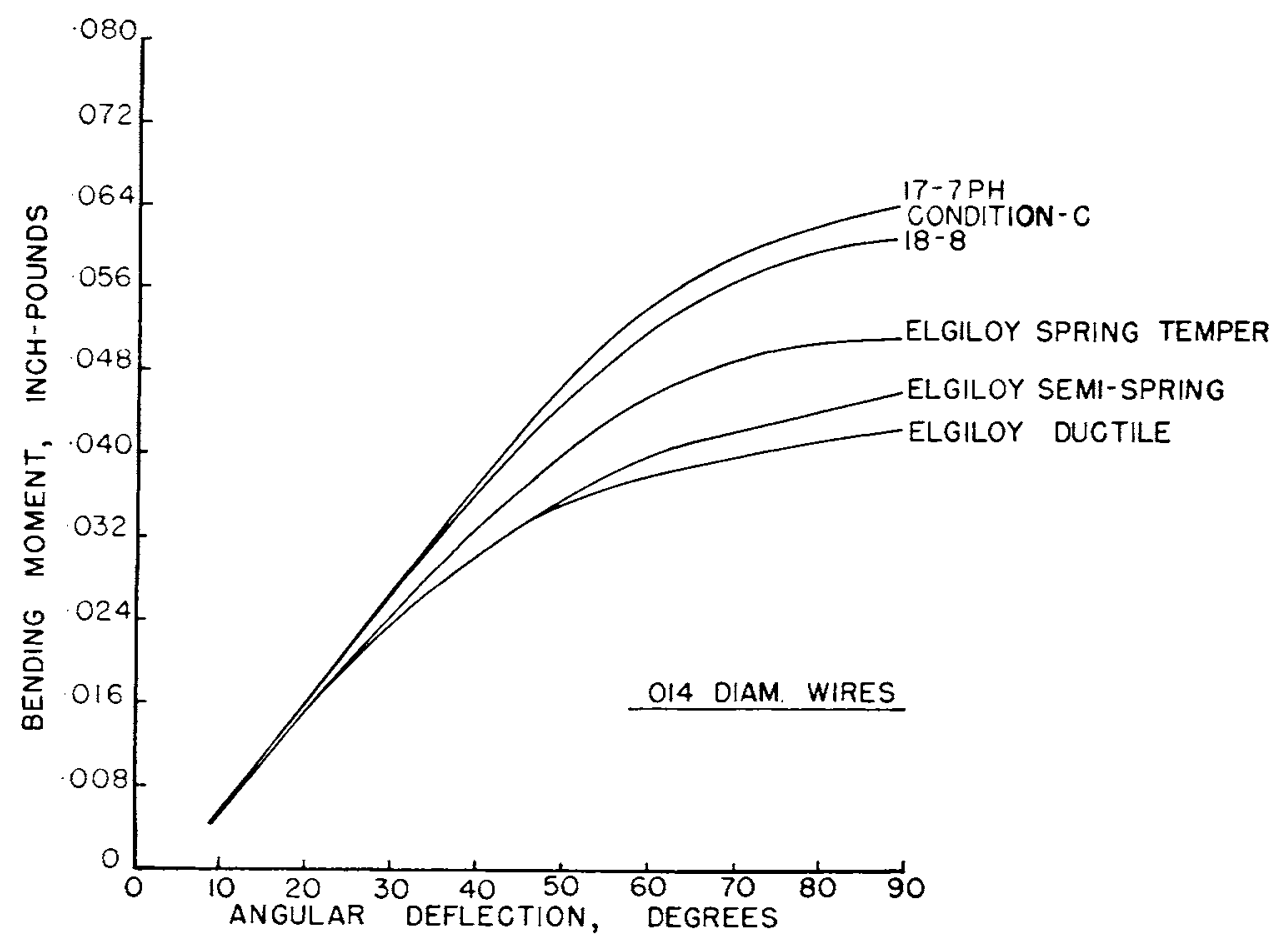

FIG. 2.-Bending moment-angular deflection curves for 0.014-inch diameter $17-7 \mathrm{PH}$ and $18-8$ stainlesssteel and cobalt-chromium-nickel wires. 
TABLE 3

MICROHARDNESS OF WIRES USED IN ORTHODONTICS

\begin{tabular}{|c|c|c|}
\hline Material & $\begin{array}{c}\text { Knoop } \\
\text { Hardness* } \\
\left(\mathrm{kg} / \mathrm{mm}^{2}\right)\end{array}$ & $\begin{array}{l}\text { Standard } \\
\text { Devia- } \\
\text { tion }\end{array}$ \\
\hline 18-8 stainless steel: & & \\
\hline Unitek. . . . . . . . . . & 518 & 12 \\
\hline $\begin{array}{l}\text { Tru-Chrome..... } \\
\text { Elgiloy: }\end{array}$ & 528 & 16 \\
\hline Spring temper. & 538 & 18 \\
\hline Semispring temper. & 528 & 20 \\
\hline Ductile.......... & 494 & 15 \\
\hline Soft. & 484 & 15 \\
\hline 17-7 PH stainless steel: & & \\
\hline Condition 'C'" & 569 & 17 \\
\hline Condition "CH900". & 654 & 16 \\
\hline $\begin{array}{l}900^{\circ} \mathrm{F} \text {. for } 15 \text { minutes re } \\
\text { sistance-heating } \ldots\end{array}$ & 613 & 7 \\
\hline $\begin{array}{l}1300^{\circ} \mathrm{F} \text {. for } 15 \text { minutes resist- } \\
\text { ance-heating } \ldots \ldots \ldots\end{array}$ & 481 & 8 \\
\hline
\end{tabular}

* 500-gm. load; 15 second time of contact.
TABLE 4

RESISTANCE TO BREAKAGE BY COLD-BENDING

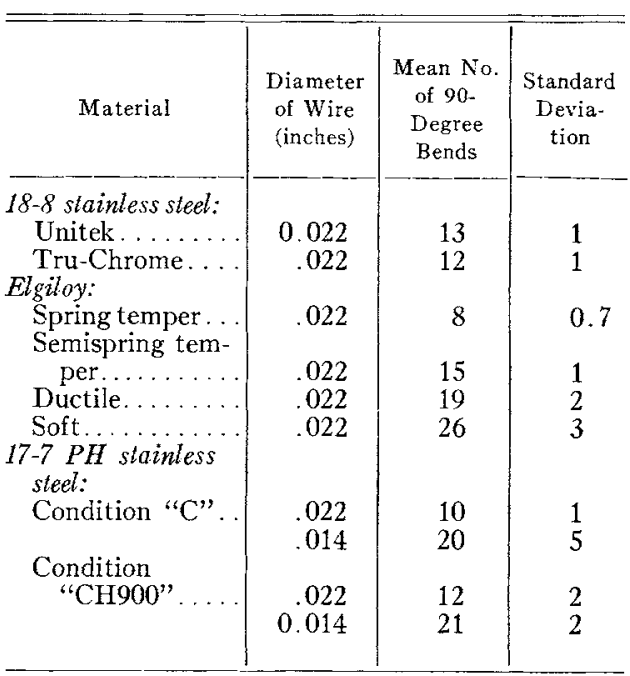

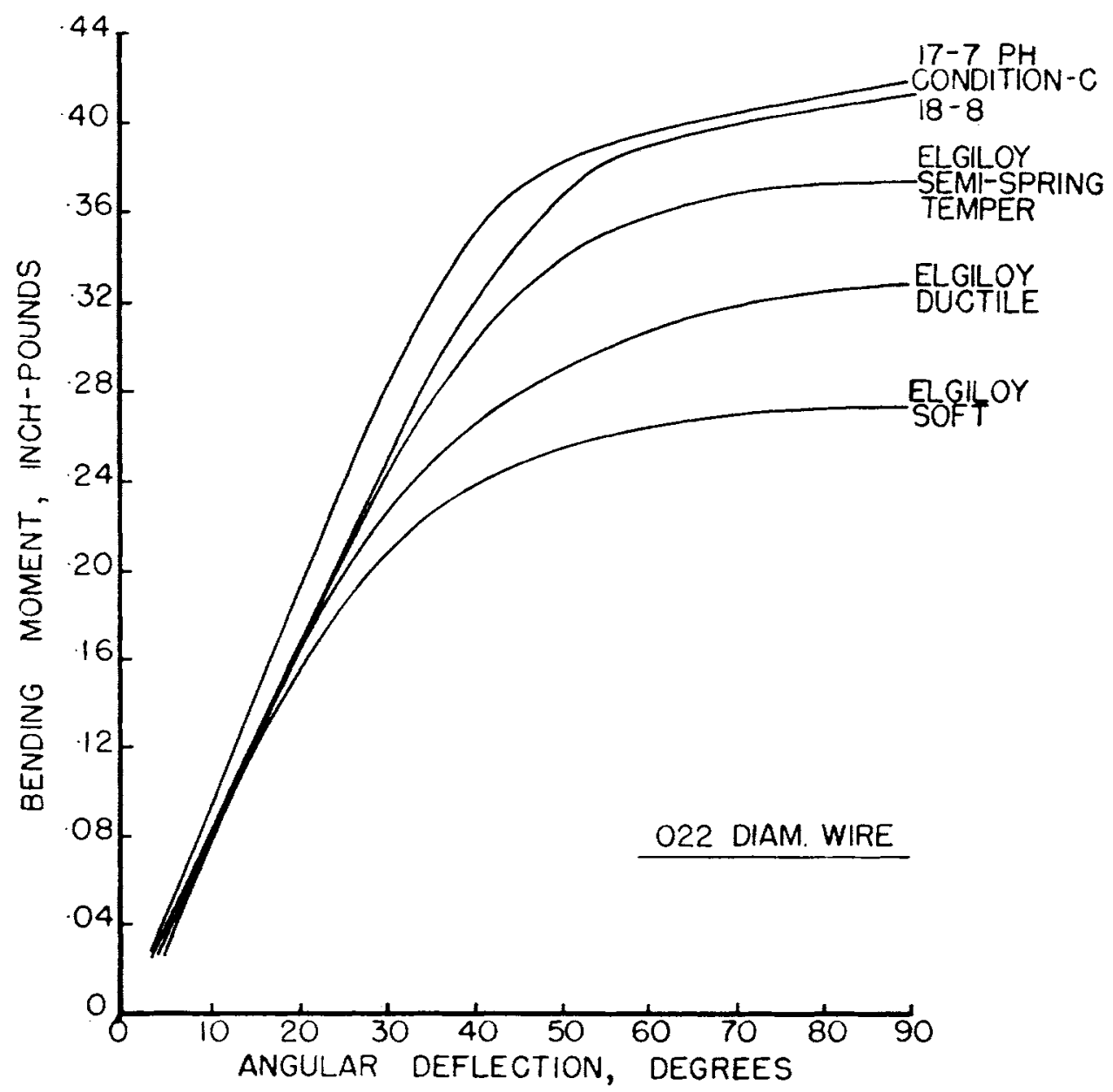

Fig. 3.-Bending moment-angular deflection curves for 0.022-inch diameter stainless-steel and cobaltchromium-nickel wires. 
In addition to the tensile, bending, and hardness qualities of the wires, the resistance of the wires to breakage by repeated bending is important in the application of these materials in orthodontics. The wires were bent over a surface having a radius of curvature of $2 \mathrm{~mm}$., which would be similar to bending the wire with smooth-nosed orthodontic pliers. The number of alternate 90-degree bends before breakage is reported in Table 4 for the various types and sizes of wires. In general, the higher the mechanical properties, the fewer the number of $90 \mathrm{de}-$ gree bends before breakage; and the smaller the diameter of the wire, the greater the number of bends possible prior to fracture. This test did not distinguish between the 18-8 and 17-7 PH stainless steels; nor did it show a difference in the 17-7 PH wire in condition "C" or "CH900." The cold-bend test did illustrate the difference in resistance to breakage by repeated bending or the four conditions of the cobalt-chromium-nickel alloy, the number of bends being twenty-six for the material in the soft condition and decreasing to eight for the spring-temper con-

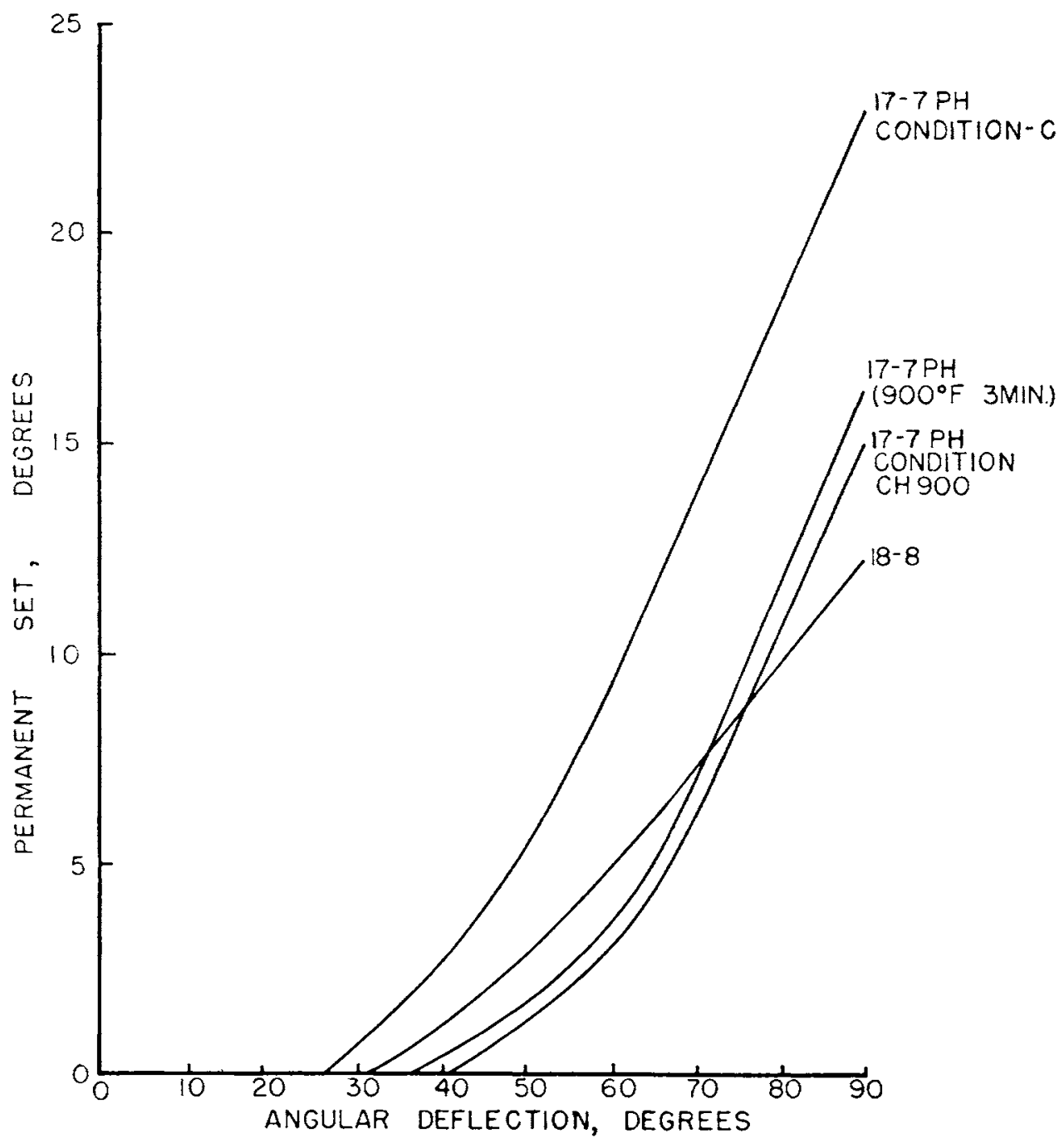

FIG. 4.-Permanent set properties of 0.014-inch diameter 17-7 PH and 18-8 stainless-steel wires 
dition. The resistance to breakage by coldbending of the spring-temper condition was comparable to the values obtained for the stainless-steel wires of the same diameter. It is apparent that the 17-7 $\mathrm{PH}$ stainless steel in the precipitation-hardened condition may have use in orthodontics, as well as using the materials in condition "C," which would involve bending the wire in the cold-worked condition followed by a precipitation-hardening treatment at $900^{\circ} \mathrm{F}$.

\section{Discussion}

The selection of 0.014- and 0.022-inch diameter wires was made on the basis that they are representative of the extremes in size which are likely to be used for round arch wires. The selection of 10 minutes for the resistance heat treatment was made because longer times were not considered clinically feasible, although considerable improvement is possible in the physical properties of 17-7 PH stainless-steel wire when heat-treated for one hour at $900^{\circ} \mathrm{F}$.

Since it was found that the modulus of elasticity did not vary significantly, the calculation of the resilience,

$$
\text { Resilience }=\frac{\left(\text { Proportional limit }{ }^{2}\right)}{2 \text { Modulus }},
$$

is primarily a function of the proportional limit. If the yield strength is taken as an indication of the proportional limit, it can be seen that resilience of the 17-7 PH wire is superior to either the $18-8$ or the cobaltchromium-nickel wire. This means more energy can be stored in the 17-7 PH wire up to the proportional limit and therefore can apply more force to a tooth being moved. since more force may not be required, alternatively a smaller wire may be used to apply the same force as with a larger wire of 18-8 stainless steel. Also, the 17-7 PH wires will be more resistant to the plastic deformation by the application of stresses in the mouth, for example, as a result of chewing.

The resistance of 18-8 stainless steel to breakage by bending is greater than for 17-7 $\mathrm{PH}$ as expected from the tensile and bending tests. It should be noted that a further improvement in the resistance of $18-8$ to breakage by cold-bending results if the wires are stress-relieved for 3 minutes at $900^{\circ} \mathrm{F}$, with the values for 0.022 -inch diameter wires in- creasing to 21 bends of 90 degrees before breakage. The 17-7 PH wires in condition "C," however, had superior resistance to permanent deformation during bending and tension.

It should also be noted that the stressrelieving of 18-8 wires for 3 minutes at $900^{\circ} \mathrm{F}$. resulted in an increase in the yield strength-values of approximately $20,000 \mathrm{psi}$ and in the tensile strength of about 10,000 psi. The practice of heating arch wires under these conditions is justified to some degree, with the realization that inadvertently heat ing to $1,300^{\circ} \mathrm{F}$. will result in substantial reduction in mechanical properties of either type of stainless-steel wire.

\section{Summary}

The tensile and bending qualities, microhardness, and resistance to breakage by bending were determined for 17-7 PH stainless steel in various conditions, and the values were compared with those obtained with 18-8 stainless steel and a cobalt-chromiumnickel alloy.

The properties of the 17-7 PH stainless steel in the cold-worked martensitic condition were comparable to those of the $18-8$ stainless steel and the spring-temper condition of the cobalt-chromium-nickel alloy, although the yield strength in tension of the 17-7 PH stainless steel was superior to any of the materials examined.

After a precipitation-hardening treatment of 1 hour at $900^{\circ} \mathrm{F}$. the strength properties of the 17-7 PH stainless steel increased markedly and were superior to the other materials. The increase in strength was accompanied by a decrease in ductility, but this decrease was not sufficiently significant to be reflected in the resistance to breakage by bending. Shorter times than 1 hour of heating at $900^{\circ} \mathrm{F}$. resulted in less improvement in strength qualities, while heating at $1,300^{\circ} \mathrm{F}$. resulted in overaging and a decrease in properties.

\section{Conclusions}

The recent development of precipitationhardenable martensitic stainless steels appears to have applications in dentistry, where the material may be formed in the work-hardened martensitic condition followed by heat treatment to increase the 
strength properties. It appears possible also to use this material in the precipitationhardened condition if only limited forming operations are to be conducted.

\section{References}

1. LenA, A. J. Precipitation Reactions in Iron Base Alloys. In Precipitation from Solid Solution, pp. 244-327. Cleveland, Ohio: American Society for Metals. 19.59. 2. Eichelman, G. H., JR., and Huld, F. C. The Effects of Composition on the Temperature of Spontaneous Transformation of Austenite to Martensite in 18-8 Type Stainless Steels, Trans. Amer. Soc. Metals, 45:77, 1953.
3. Ludwigson, D. C., and Hali, A. M. The Physical Metallurgy of Precipitation-Hardenable Stainless Steels. Defense Metals Information Center Report 111. Battelle Memorial Institute, Columbus, Ohio, April $20,1959$.

4. Fisher, J. C., Holloman, J. H., and Turnbuld, D. Kinetics of the Austenite-Martensite Transformation, Trans. Amer. Inst. Mech. Eng., 185:691, 1949.

5. Greninger, A. B., and Troinno, A. R. The Mechanism of Martensite Formation, Trans. Amer. Inst. Mech. Eng., 185:590, 1949.

6. Craig, R. G., and Peyton, F. A. Physical Properties of Carbon Steel Root-Canal Files and Reamers, Oral Surg., 15:213, 1962

7. Wrlkinson, J. V. Some Metallurgical Aspects of Orthodontic Stainless Steel, Amer. J. Orthodont, 48: 192, 1962 . 